\title{
Book Review: Risk Management in the Global Supply Chain by Thomas A. Cook
}

\author{
Alexander Franco, Ph.D. \\ Stamford International University, Graduate School of Business \\ alexander.franco@stamford.edu
}

As supply chain management has taken on more importance in the business world, there has been a plethora of books written to facilitate professional management of logistics. The past five years has seen many works that have focused on more efficient or lean managerial strategies while others have concentrated on the challenges of green logistics and sustainability. Still others have been industry-specific in their examination regarding areas such as food networks, pharmaceuticals, chemicals, clothing supply, and even commercial aerospace. However, very few have focused on logistical concerns regarding risk management.

The author of this work approaches the challenge of risks through a comprehensive model which he refers to as "enterprise risk management" (ERM) (p. 4). This strategic business discipline begins by examining the full spectrum of risks - not just losses to inventory - but also strategic, financial, and operational risks. It then calls for the development of a company-specific interrelated risk portfolio that targets a company's internal and external environments and issues relating to suppliers, carriers, customs clearance, and inventory storage as well as financial concerns such as declining revenue, loss of market share, and the deterioration of a company's brand or reputation.

ERM is an all-encompassing approach which the author describes as akin to practicing defensive driving of a vehicle. "You are focused on the road ahead, but you are looking at the side and rear view mirrors...[while] viewing the dashboard and seeing how the engine is performing" (p. 8). This multi-focused orientation has management assessing issues that are often intertwined in the causes of problems as well as in their resolutions. The ones examined in the book included property loss, receivable management, political risk, insurance, security (including terrorism), technology and cyber issues, personnel conflict, contract management, and bribery issues (e.g., dealing with the Foreign Corrupt Practices Act of 1977 - an American legislation), as well as geophysical and environmental issues.

The author, with thirty-five years of experience in business and logistics, provides a dozen mini-case studies to illustrate key points involving different industries. He also provides illustrations of important documents involved in various processes. Seven pages are also devoted to an area that is often ignored in risk management discussions: the risks involved in reputation branding and marketing. Cultural considerations are also examined.

In the final chapter of the book, the author integrates and synthesizes all the information he presented in the previous chapters into a comprehensive best practice strategy to deal with global supply chain risk management. This strategy is presented in the form of a ten-step master plan that is outlined and discussed in ten pages of the book. Following the last chapter, the author included eight comprehensive appendices. The first 
four provide valuable glossaries on general business terms, contractual terms, international trade terms, and business acronyms. Other appendices deal with concerns such cybersecurity, conflict minerals, and customs considerations as well as relative documents involving these issues.

The examination of risk is vital within the field of supply chain management. This work provides a valuable addition to this effort. The author, who has penned nineteen books, is a very effective communicator. His writing is straight forward and clearly explains a wide range of material without excessive technical jargon. Much of this may be due to the decades of experience he acquired in the real word of business - always a plus for any academician in a business school. For these reasons, this book can be understood by managers and business professionals as well as curious laymen. In addition, it is written in a way to teach and is, therefore, suitable for undergraduate and graduate business courses.

Citation: Alexander Franco, Book Review: Risk Management in the Global Supply Chain by Thomas A. Cook. American Research Journal of Business and Management; V3, I1; pp:1-2

Copyright (C) 2017 Alexander Franco, This is an open access article distributed under the Creative Commons Attribution License, which permits unrestricted use, distribution, and reproduction in any medium, provided the original work is properly cited. 